Supplement of Atmos. Chem. Phys., 21, 15431-15445, 2021

https://doi.org/10.5194/acp-21-15431-2021-supplement

(C) Author(s) 2021. CC BY 4.0 License.

(c) (i)

Supplement of

\title{
Aerosol transport pathways and source attribution in China during the COVID-19 outbreak
}

\section{Lili Ren et al.}

Correspondence to: Yang Yang (yang.yang@ nuist.edu.cn)

The copyright of individual parts of the supplement might differ from the article licence. 


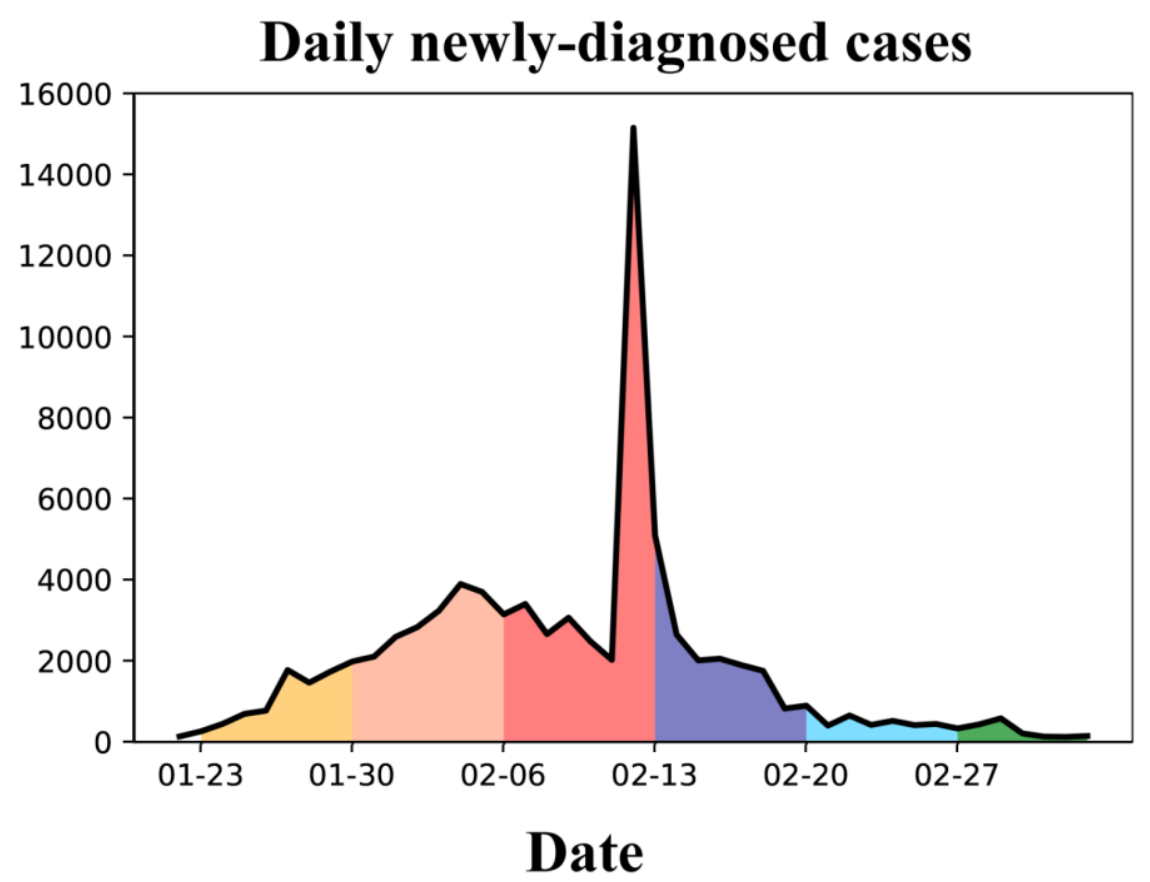

Figure S1. The number of daily newly-diagnosed cases in China from January 23 to February 27, 2020, during the COVID-19. 


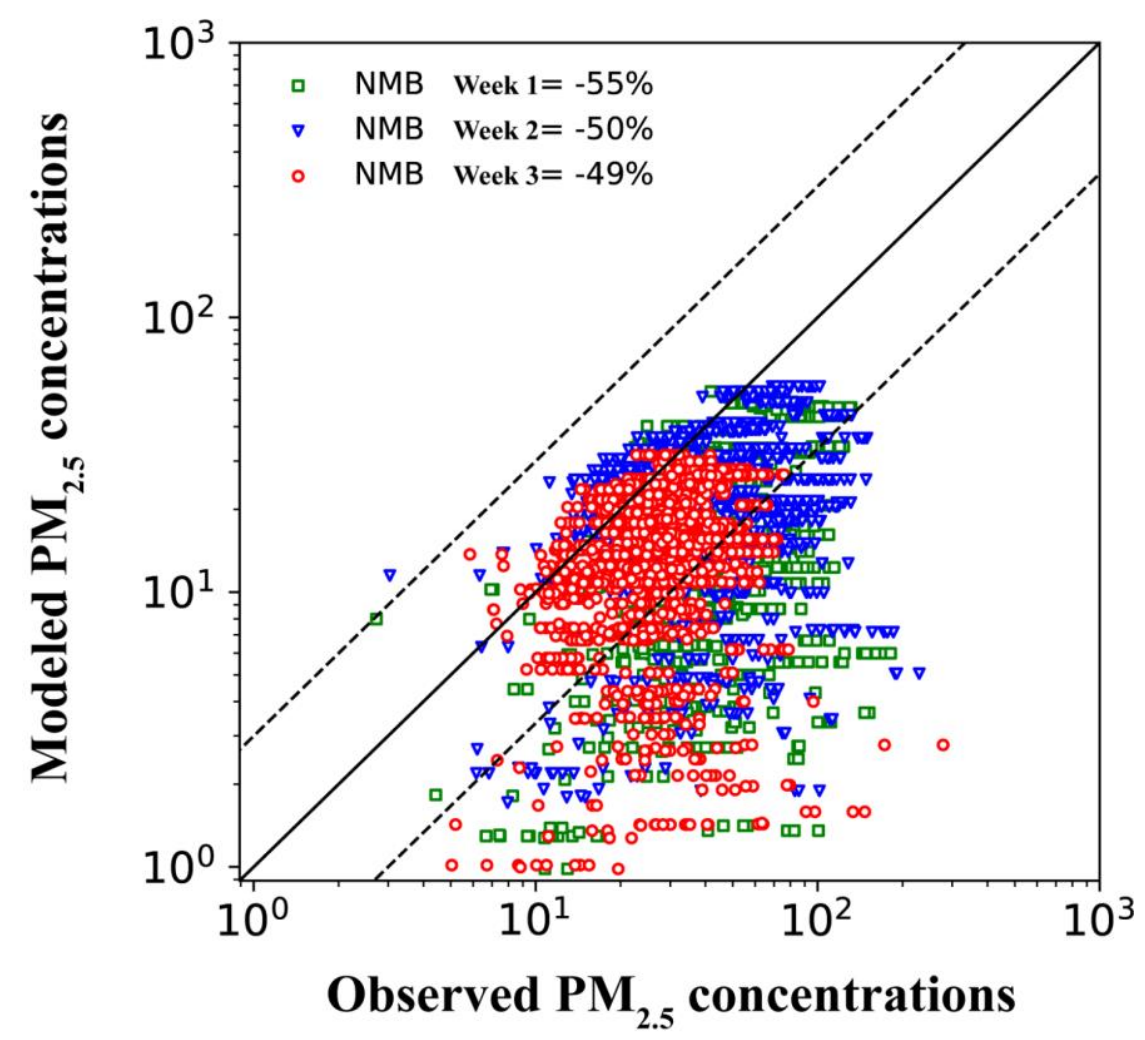

Figure S2. Comparisons of observed and modeled mean near-surface concentrations of $\mathrm{PM}_{2.5}$ (units: $\mu \mathrm{gm}^{-3}$ ) in China during the three time periods. Solid lines mark the 1:1 ratio, and dashed lines mark the 1:3 and 3:1 ratios. Normalized mean bias (NMB) between observation and simulation is shown at the top left of the panel. $N M B=100 \% \times \sum\left(M_{i}-O_{i}\right) / \sum O_{i}$, where $M_{i}$ and $O_{i}$ are the modeled and observed values at site $i$, respectively. 

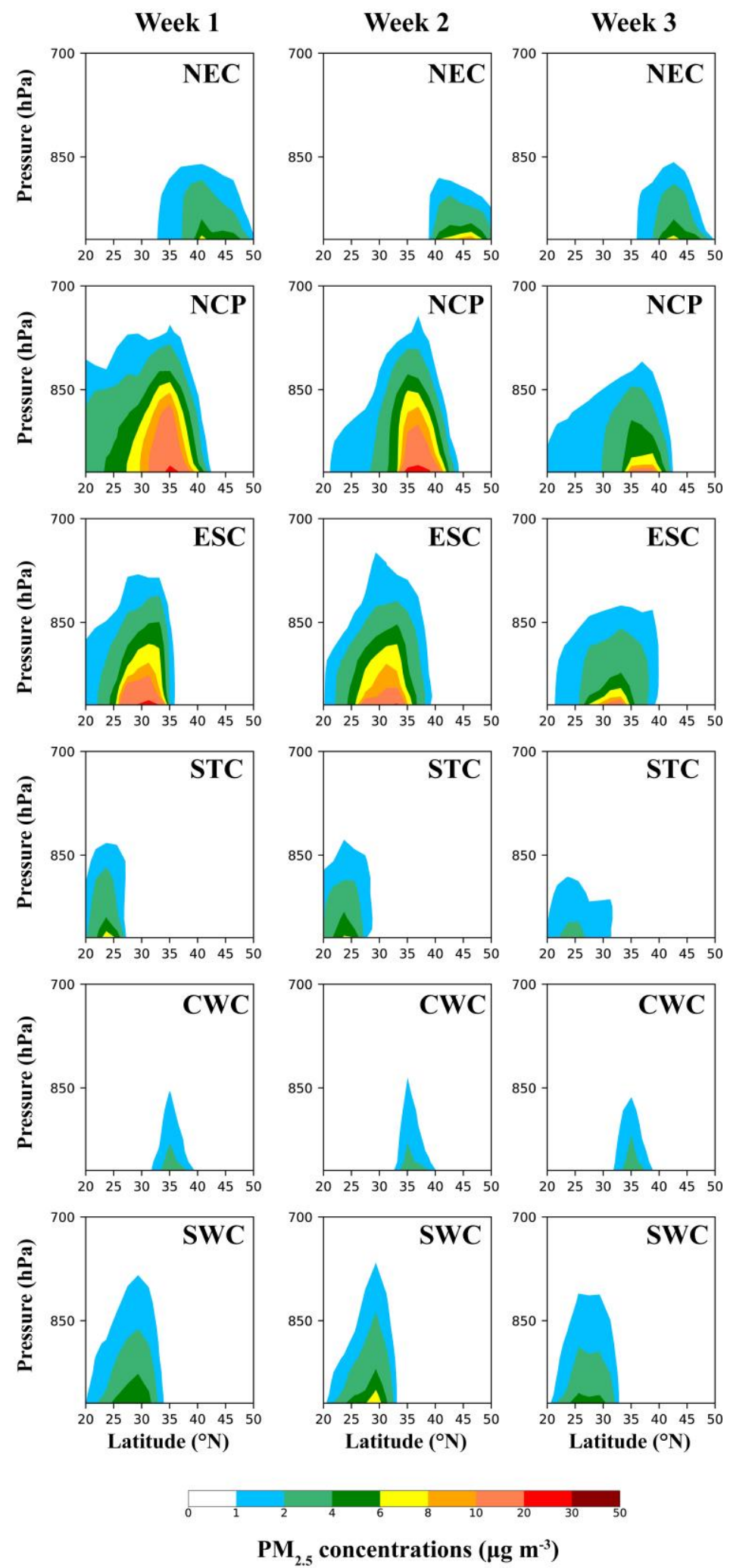

Figure S3. Vertical and latitudinal cross section of mean $\mathrm{PM}_{2.5}$ concentrations $\left(\mu \mathrm{g} \mathrm{m}^{-3}\right)$ averaged over the longitudinal extent of six major source regions originating from local emissions (within the corresponding source region) during the three time periods. 

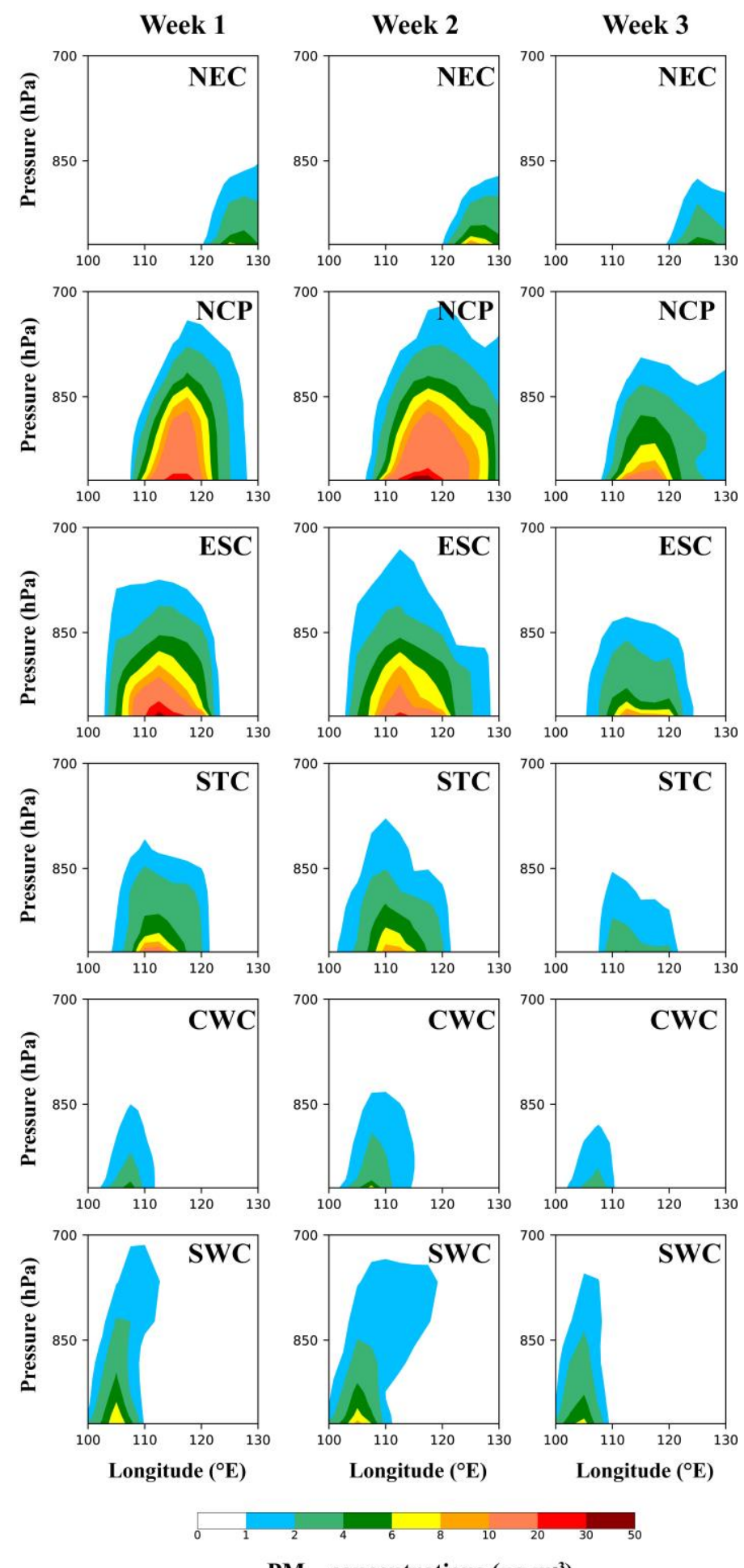

$\mathrm{PM}_{2.5}$ concentrations $\left(\mu \mathrm{g} \mathrm{m}^{-3}\right)$

Figure S4. Vertical and longitudinal cross section of mean $\mathrm{PM}_{2.5}$ concentrations $\left(\mu \mathrm{g} \mathrm{m}^{-3}\right)$ averaged over the latitudinal extent of six major source regions originating from local emissions (within the corresponding source region) during the three time periods. 


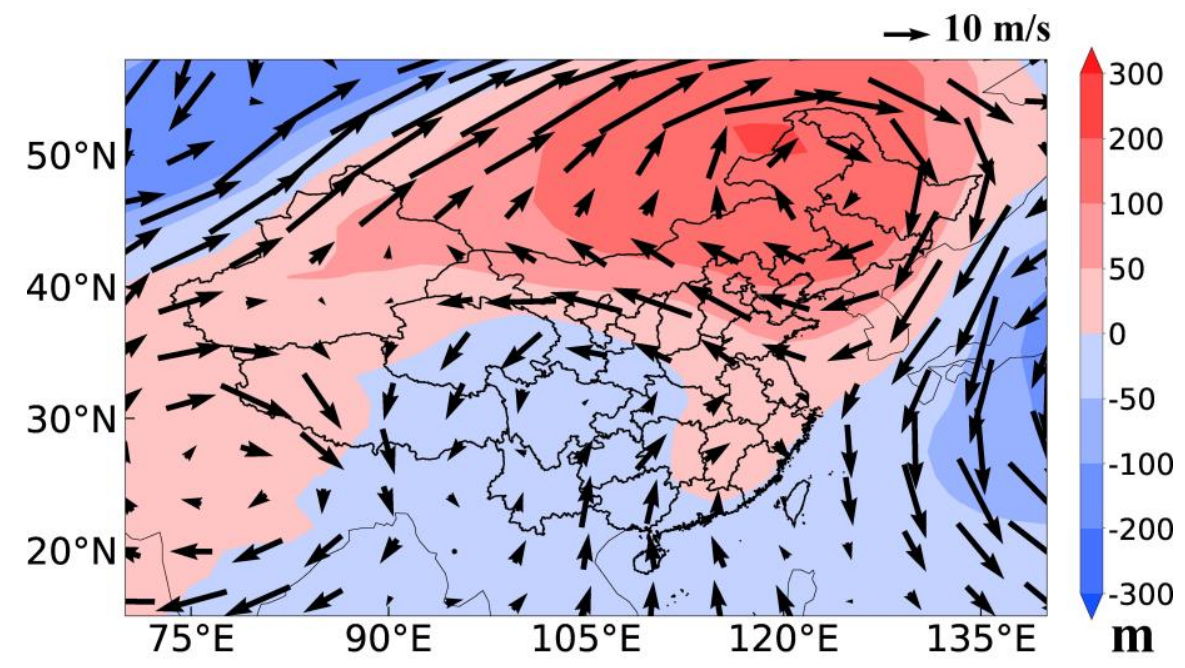

Figure S5. Composite differences in $500 \mathrm{hPa}$ geopotential height (GPH, m) and $500 \mathrm{hPa}$ wind ( $\mathrm{m} \mathrm{s}^{-1}$, vector) between February 11, 2020 and monthly mean of February 2020. 
(a) Local contribution

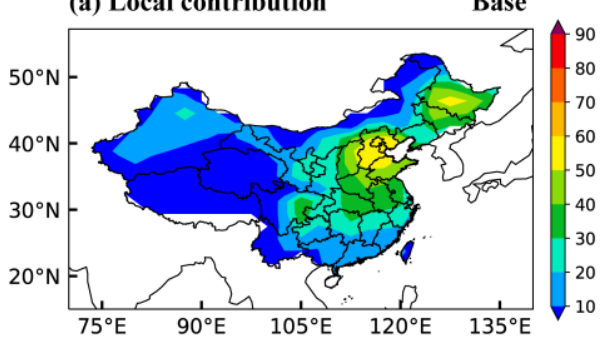

(c) RCN contribution

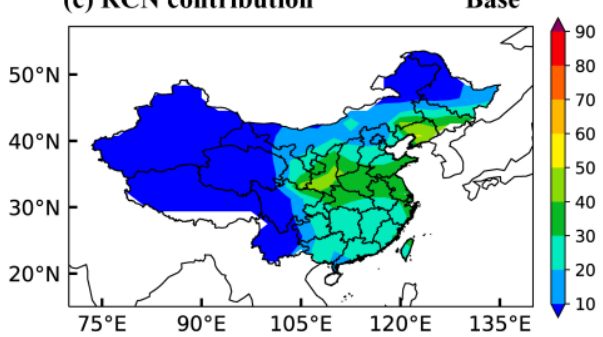

(e) ROW contribution

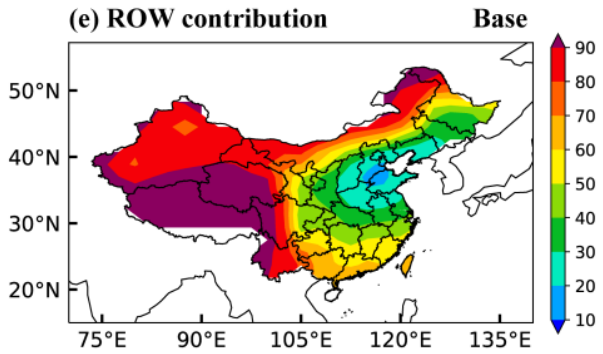

(b) Diff. Local contribution

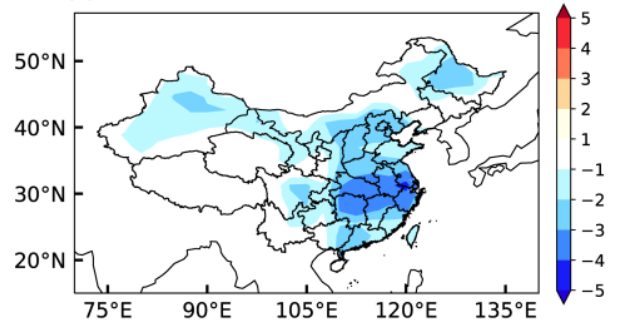

(d) Diff. RCN contribution

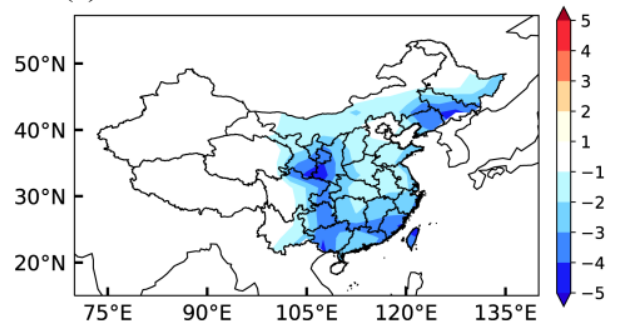

(f) Diff. ROW contribution

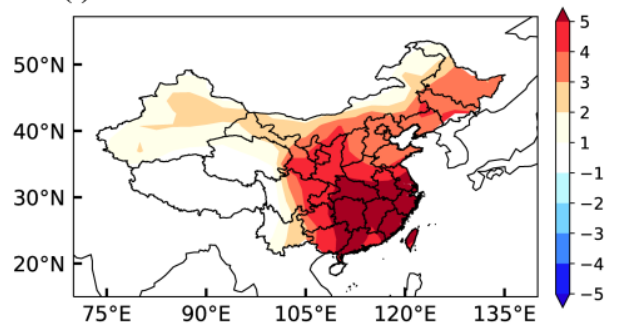

Figure S6. Relative contributions (\%) in Baseline simulation (left) and differences in relative contributions (\%) between Covid and Baseline simulations (right) of local emissions (top), the emissions from the rest of China (RCN) (middle) and all sources outside China (rest of the world, ROW) (bottom) to $\mathrm{PM}_{2.5}$ column burden in February 2020. 